\title{
The living environment and children's fears following the Indonesian tsunami
}

\section{Citation}

Du, Ye Beverly, Christopher Thomas Lee, Desy Christina, Myron L. Belfer, Theresa S. Betancourt, Edward James O'Rourke, and Judith S. Palfrey. 2011. "The Living Environment and Children's Fears Following the Indonesian Tsunami." Disasters 36 (3) (November 21): 495-513. doi:10.1111/ j.1467-7717.2011.01271.x.

\section{Published Version}

doi:10.1111/j.1467-7717.2011.01271.x

\section{Permanent link}

http://nrs.harvard.edu/urn-3:HUL.InstRepos:26480215

\section{Terms of Use}

This article was downloaded from Harvard University's DASH repository, and is made available under the terms and conditions applicable to Other Posted Material, as set forth at http:// nrs.harvard.edu/urn-3:HUL.InstRepos:dash.current.terms-of-use\#LAA

\section{Share Your Story}

The Harvard community has made this article openly available.

Please share how this access benefits you. Submit a story.

\section{Accessibility}




\title{
The living environment and children's fears following the Indonesian tsunami
}

\author{
Ye Beverly Du, Christopher Thomas Lee, Desy Christina, Myron L. Belfer, Theresa S. \\ Betancourt, Edward James O'Rourke, and Judith S. Palfrey ${ }^{1}$ \\ Ye Beverly Du, Resident in Adult Psychiatry, Columbia-New York Presbyterian Hospital, New \\ York, United States; Christopher Thomas Lee, Medical Student, Harvard Medical School, Boston, \\ United States; Desy Christina, Psychologist Consultant, International Organization for Migration, \\ Meulaboh, Indonesia; Myron L. Belfer, Professor of Psychiatry, Department of Psychiatry, \\ Children's Hospital Boston, Harvard Medical School, Boston, United States; Theresa S. \\ Betancourt, Assistant Professor of Child Health and Human Rights, Department of Global Health \\ and Population Director, Research Program on Children and Global Adversity, François-Xavier \\ Bagnoud Center for Health and Human Rights, Harvard School of Public Health, Boston, United \\ States; Edward James O'Rourke, Faculty Director, Student International Programs, Scholars in \\ Medicine Office at Harvard Medical School, Boston, United States; Judith S. Palfrey, Senior \\ Associate in Medicine, Children's Hospital, Department of Medicine, Boston, United States
}

\section{Abstract}

The tsunami that struck South-east Asia on 26 December 2004 left more than 500,000 people in Aceh, Indonesia, homeless and displaced to temporary barracks and other communities. This study examines the associations between prolonged habitation in barracks and the nature of fears reported by school-age children and adolescents. In mid-2007, 30 months after the tsunami, the authors interviewed 155 child and parent dyads. Logistic regression analysis was used to compare the fears reported by children and adolescents living in barracks with those reported by their peers who were living in villages. After adjusting for demographic factors and tsunami exposure, the data reveals that children and adolescents living in barracks were three times more likely than those living in villages to report tsunami-related fears. The study demonstrates that continued residence in barracks 30 months after the tsunami is associated with higher rates of reporting tsunami-related fears, suggesting that barracks habitation has had a significant impact on the psychological experience of children and adolescents since the tsunami.

\section{Keywords}

children; displacement; environment; fears; Indonesia; post-traumatic stress disorder (PTSD); psychiatry; tsunami

\footnotetext{
(C) 2012 The Author(s)Journal compilation () Overseas Development Institute, 2012

Correspondence Ye Beverly Du, 1051 Riverside Dr., Box 97, New York, NY 10032, United States. Telephone: +1 2125435551. yd2209@columbia.edu.

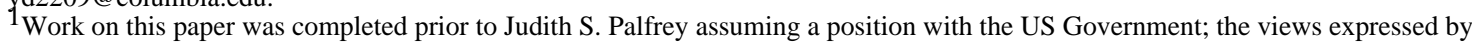
the author are solely her own and not the views of the US Government.
} 


\section{Introduction}

After the 2004 Indian Ocean tsunami, more than 500,000 individuals in Aceh, Indonesia, were internally displaced to temporary barracks and other host communities while awaiting the construction of houses (USAID, 2005). Meulaboh, a city in Aceh, was the closest city to the epicentre of the tsunami earthquake. Families in Aceh that lost their homes were displaced to living shelters (barracks) that had been built quickly to house large numbers of people for up to six months. Barracks were often located far from schools and places of employment, setting additional hurdles for families that sought to sustain the livelihoods they once had. Many communities were dispersed in the process of relocating to barracks and, as a result, the close social networks common in traditional villages were often lacking in the barracks. Due to delays in land distribution and construction, hundreds of families continued to live in these barracks for more than two years after the tsunami, while still awaiting their homes to be rebuilt.

This study explores the psychological impact the displacement into barracks had on children and adolescents. Kiran Rao of the National Institute of Mental Health and Neuro Sciences in Bangalore describes four stages of intervention: the rescue phase (0-2 weeks post disaster), the relief phase (2-6 months post disaster), the rehabilitation phase (1-2 years post disaster), and the rebuilding phase (many years post disaster) (Rao, 2006). For various reasons, including funding and global interest, most disaster research has focused on the first two phases. By 2007, with the withdrawal of relief agencies, many sources of aid had dissipated in the Aceh region, potentially leaving needs of the displaced unmet. This research seeks to help fill the knowledge gap with regard to the latter two phases of post-disaster intervention.

Several studies have been undertaken on the psychological impact of the tsunami on children and adolescents. In Thailand, the prevalence of post-traumatic stress disorder (PTSD) symptoms two to nine months after the tsunami was found to be 11-13 per cent among affected youths aged 7-14 (Thienkrua et al., 2006). In southern India, eight months after the tsunami, rates of PTSD among children and adolescents in affected areas were as high as 70 per cent (John, Russell, and Russell, 2007). After two years, rates of PTSD among tsunami-affected schoolchildren in Thailand were found to be 7.6 per cent (Piyasil et al., 2007); after three years, 11 per cent of tsunami-affected schoolchildren who had been diagnosed with PTSD one year after the disaster continued to have chronic PTSD (Ulartinon et al., 2008). Factors associated with increased risk of psychopathology included family psychopathology and severity of exposure to the tsunami (Thienkrua et al., 2006; Vijayakumar, Kannan, and Daniel, 2006).

The majority of post-tsunami studies focus on diagnostic constructs and psychopathology such as PTSD, depression, and anxiety. Although a diagnostic approach is useful in understanding some dimension of distress in the population, some question the cultural validity of diagnostic criteria and the accuracy with which they represent psychopathology without correlation with psychosocial impairment (Belfer, 2006). From a practical standpoint, diagnoses may have limited utility in designing interventions in a community where psychiatric resources are scarce and may actually harm individuals via unnecessary stigmatization (Belfer, 2006; Stichick, 2001; Summerfield, 2001). This study utilizes a non- 
diagnostic, non-stigmatizing construct to understand the psychological experience and recovery of tsunami-affected children.

Displacement affected large proportions of tsunami survivors for months to years following the disaster, but few studies address the impact of prolonged displacement on child and adolescent mental health. A meta-analysis on refugee mental health shows that institutional and temporary private accommodation led to greater risk of mental health outcomes for refugees than did permanent private accommodation (Porter and Haslam, 2005). The authors argue that:

the enduring contextual post-migration stress that refugees face-including marginalization, socioeconomic disadvantage, acculturation difficulties, loss of social support and 'cultural bereavement' - must be recognized (Porter and Haslam, 2005, p. 603).

The 'psychology of place' is an emerging area of research that also considers the impact of environment and displacement on the psychological well-being of individuals (Fullilove, 1996). This paper identifies a similar need for the recognition of multidimensional factors, such as the living environment, with respect to displaced persons in post-disaster settings, not least to better inform what measures can be taken to protect child and adolescent mental health.

The goal of this study is thus threefold: to assess the long-term mental health outcomes for tsunami-affected children and adolescents, to determine the impact of prolonged displacement on these outcomes, and to characterize these outcomes in a non-diagnostic language.

Preliminary contact with the families in the barracks revealed children's fears as significant symptoms. Many parents voiced concern about their children's fears of inclement weather impacting their ability to attend school and take part in other activities. This observation led to the effort to learn more about children's and adolescents' fears in the post-tsunami population and to understand their etiology. Rachman (1977) proposes that fears are acquired through direct conditioning, vicarious learning, and information or instruction. In 1998, King, Gullone, and Ollendick conducted a review that demonstrates overall support of Rachman's theory. Many instruments have been used in several populations around the world to characterize patterns of fear among children. One such tool is the Fear Survey Schedule for Children (FSSC), originally developed by Scherer and Nakamura in 1968 and subsequently revised into the FSSC-R and FSSC-II. The FSSC is a questionnaire that asks respondents to rate a list of common fears from 1 to 3 on a Likert scale of severity (Ollendick, 1983). The FSSC-R is displayed in Figure 1. Rating numbers are summed to obtain total fear scores overall or within subscales.

Fear of death and danger, including environmental fears, such as of earthquakes, is the most common fear category reported (Burnham and Gullone, 1997; Muris et al., 2000).

Environmental fears are also increased by the experience of a disaster, as demonstrated by a study that compares children who were affected by recent earthquakes to others who were not affected (Karairmak and Aydin, 2008). Fearfulness in general decreases with age 
(Gullone and King, 1997); in addition, children of different age groups report different types of fears at different rates (Bauer, 1976). Girls report higher levels of fears than boys (Burnham and Gullone, 1997). Children of lower socio-economic status report more fears (Burnham and Gullone, 1997; Erol and Sahin, 1995; Gullone and King, 1992). The reporting of fears also varies by culture. In a study of African children, Nigerian children reported higher total fear than Kenyan children, and Christian children reported higher levels of fear in several categories compared to Muslim children (Ingman, Ollendick, and Akande, 1999).

This study examines the differences in self-reported fears of children and adolescents who were living in barracks as compared to children who were living in villages 30 months after the tsunami. In the latter group, respondents who had previously lived in barracks but moved back to a village were compared to those who had never lived in barracks but had remained in villages since the tsunami. This study began with the hypotheses that:

- children and adolescents who were living in barracks would report tsunami-related fears more frequently than those who were living in villages; and

- children and adolescents who had previously lived in barracks but had moved back to villages would report tsunami-related fears less frequently than those who had continued to live in barracks and at rates similar to children and adolescents who had never lived in barracks.

\section{Methods}

This is a post-disaster, naturalistic, cross-sectional, direct interview-based pilot study using a convenience sample of parents and children who volunteered. The survey was conducted over six weeks, from June to August 2007. The study was facilitated by the ongoing commitment of the International Organization for Migration (IOM) to support health-related services and was part of IOM's larger psychosocial assessment of the regional population. The Harvard Medical School Institutional Review Board and the Meulaboh District Health Office approved all study protocols. Local approval of the study and agreement for cooperation was obtained from local leaders and chiefs from all study sites at preliminary meetings.

\section{Respondents}

Given that the study was part of a larger psychosocial assessment for IOM, research was limited to the eight barracks in the region under IOM surveillance. Four barracks were randomly selected from the eight in the districts of Aceh Barat and Nagan Raya, the districts surrounding the city of Meulaboh. For each of the four study barracks, the investigators chose one comparison village that was located within one kilometre of the corresponding study barracks. The investigators recruited children and adolescents aged 5-14 and their parents through door-to-door sampling within the chosen sites. In addition, the team worked closely with village chiefs and barracks leaders, who informed the community of the study and identified areas with a high density of children who would be suitable respondents. The team also asked families for referrals to neighbours who had children and adolescents of the desired age. 
The aim was to interview about 15 to 20 children from each site, along with their parents. Only one child was interviewed per household and only children with primary caregivers at home were recruited. An effort was made to obtain a balanced distribution with respect to age and gender. The parents and children were predominately ethnically Achenese and Muslim.

\section{Survey}

Upon recruiting families with children and adolescents of the desired age, the investigators introduced themselves as affiliates of IOM and asked the parents if they were interested in participating in a survey. If they agreed, the investigators presented a more formal description and introduction regarding the study, after which prospective participants were given the option of officially participating by signing a written consent. The investigators obtained written assent from all children and adolescents as well prior to proceeding with the interview. Demographic information, including on age, sex, the father's level of education, and the distance of the original home from the coast, was obtained from parents.

Due to the fact that this was part of a larger psychosocial assessment that involved a number of other questions and in view of time constraints, the study team utilized two simple questions to assess the respondents' fears instead of a more detailed survey such as the FSSC. Children and adolescents were asked two questions:

1. 'Are you afraid of anything?' and, if the response to the first question was 'Yes',

2. 'What are you afraid of?'

The second question was open-ended and respondents were free to list zero to several fears, which were recorded verbatim by the interviewer. The survey was translated into Indonesian, back-translated into English, and conducted by Indonesian-speaking interpreters.

\section{Data analysis}

After the survey was completed, fears reported by the respondents were categorized into four main groups based on dominant themes: 1) tsunami-related, 2) animals and people, 3) supernatural or unknown, and 4) god (see Table 1). All of the environmental fears reported in the sample were tsunami-related and were thus called 'tsunami-related fears'. If respondents answered 'Yes' to the question 'Are you afraid of anything?', they were considered to have reported fears in general. Five binary outcome variables were examined: 1) the reporting of fears in general, 2) the reporting of tsunami-related fears, 3) the reporting of fears of animal and people, 4) the reporting of fears of the supernatural or the unknown, and 5) the reporting of a fear of god.

The study's main covariate of interest was the respondent's living environment. At the time of the study, respondents were either living in barracks (BAR) or in a village (VIL). The VIL group included two sub-groups: respondents who had previously lived in barracks and subsequently moved to the village before the study period (VIL-B) and respondents who had not lived in barracks following the tsunami (VIL-V). Given that age, sex, exposure to disaster, and socio-economic status have previously been identified as determinants of 
variation of fears in children and that they are also possibly associated with the main covariate of interest, this study attempts to control for these factors in the final multivariate analyses.

Respondents were divided into three age groups based on the Piagetian stages of cognitive development: the preoperational stage (5-6), the concrete operational stage (7-10), and the formal operational stage (11-14) (Piaget, 1946). Similar age groupings have been used in past studies of fear in children (Burnham and Gullone, 1997; Gullone and King, 1992; Muris et al., 2000; Schaefer, Watkins, and Burnham, 2003). A father's level of education was chosen to approximate socio-economic status $(0=$ none, $1=$ elementary school, $2=$ junior high, $3=$ high school, $4=$ college). The study also controls for exposure to the tsunami itself, separate from displacement into barracks following the tsunami, approximated by the distance of the respondent's original home from the coastline. Age group is treated as a categorical variable whereas the father's level of education and distance of the original home from the coast are treated as continuous variables.

The data was entered into a password-protected database and brought back to the United States for analysis. Variable characteristics and basic percentages were obtained through Microsoft Excel version 11.5.4. The continuous variables-the distance of the original home from the coast and the father's level of education-were tested for normality and were not found to be normally distributed. A zero-order correlation matrix with Spearman correlation coefficients was obtained to determine relationships between all covariates and outcome variables. A multivariate logistical regression model was generated for each of the five outcome variables, describing the relationship between the outcome variable and the child's living environment, adjusting for age, sex, father's education level, and distance of the original home from the coastline. The models were first generated by comparing the BAR group with the VIL group and then re-generated after separating the VIL group into the VIL$B$ and VIL-V subgroups. Normality testing, a calculation of correlation coefficients, and odds ratios and multivariate logistical regression were performed using SAS versions 9.1 and 9.2 .

\section{Results \\ Sample characteristics}

A total of 155 children and adolescents were interviewed, of which 40.0 per cent were in the BAR group ( $n=62)$ and 60.0 per cent were in the VIL group $(n=93)$ at the time of the interview. See Table 2 for a full description of sample characteristics. Children in the VIL-B group previously lived in barracks for 2-23 months and had been living in villages for at least five months prior to the interview ( $\mathrm{n}=27,17.4$ per cent). There was a slight predominance of boys (53.6 per cent boys vs. 46.5 per cent girls).

About 70 per cent of the children and adolescents in the sample reported having fears. See Table 3 for basic fear-reporting statistics. The most common specific fear reported in the sample was the fear of ghosts, which was reported by 46.3 per cent of the respondents, followed by the fear of a tsunami, reported by 13.0 per cent. Tsunamis, wind, and earthquakes were among the top ten most frequently reported specific fears. 


\section{Correlations}

A zero-order correlation matrix of Spearman correlation coefficients was constructed to determine the relationships between pairs of covariates and outcome variables. Significance was defined at $\mathrm{p} \unlhd \mathbf{0 5}$. The reporting of having fears in general was significantly inversely correlated with being in the BAR group versus the VIL group $(\mathrm{p}=0.001)$ and positively correlated with the distance of the original home from the coast $(\mathrm{p}=0.004)$. When the VIL group was broken down into sub-groups-VIL-B and VIL-V—analysis of variance demonstrated a significant difference among the groups BAR, VIL-B, and VIL-V in the reporting of having fears in general $(\mathrm{p}=0.005)$. Having tsunami-related fears was positively correlated with being in the BAR group versus the VIL group $(\mathrm{p}=0.009)$ and negatively correlated with the distance of the original home from the coast $(\mathrm{p}=0.047)$. Analysis of variance demonstrated a significant difference among the groups BAR, VIL-B, and VIL-V in the reporting of tsunami-related fears $(\mathrm{p}=0.034)$. Being in the BAR group versus the VIL group was negatively correlated with the distance of the original home from the coast $(p<0.0001)$. Having fears of the supernatural or the unknown was positively correlated with female sex $(\mathrm{p}=0.015)$.

\section{Multivariate regression model results}

Multivariate logistical regression models of the five outcome variables adjusted for age, sex, the father's level of education, and the distance of the respondent's original home from the coast. After adjusting for these covariates, the reporting of fears in general by respondents in the BAR group was not significantly more common or rare than by those in the VIL group. In fact, no covariates were significant predictors of the reporting of having fears in general in the multivariate model (see Table 3 for adjusted odds ratios).

Children and adolescents in the BAR group were approximately three times more likely to report tsunami-related fears than those in the VIL group $(\mathrm{OR}=2.97[1.00-8.84] \mathrm{p}=0.050)$. Respondents in the BAR group were approximately four times more likely to report tsunami-related fears compared to those in the VIL-B group; however, this result did not reach statistical significance $(\mathrm{OR}=4.20[0.97-18.18] \mathrm{p}=0.055)$. There was no significant difference between the VIL-B and VIL-V groups. No other covariates showed significant effects in the multivariate models on the reporting of tsunami-related fears.

Children and adolescents in the BAR group were significantly less likely to report fears of animals and people compared to those in the VIL group ( $\mathrm{OR}=0.30[0.10-0.90] \mathrm{p}=0.033)$. Girls were more likely than boys to report fears of the supernatural or the unknown $(\mathrm{OR}=2.74$ [1.11-6.79] $\mathrm{p}=0.029)$. No covariates demonstrated significant relationships with the reporting of a fear of god.

\section{Discussion}

The study finds that, after adjusting for potential confounders, children and adolescents who continued to live in a barracks environment 30 months after the tsunami reported tsunamirelated fears three times more frequently than those who lived in villages, confirming the first hypothesis of this study. This finding is consistent with a recent meta-analysis on pre- 
displacement and post-displacement factors associated with the mental health of refugees, in which worse mental health outcomes were found among refugees living in institutional accommodations (Porter and Haslam, 2005).

The second hypothesis is partly supported by the results. This study predicted that there would be no significant difference in the frequency of reporting tsunami-related fears between respondents in villages who lived in barracks and respondents who had never lived in barracks; this premise was confirmed by the results. A related prediction was that respondents in villages who previously experienced living in barracks would report tsunamirelated fears less frequently than those who continued to live in barracks, but this result did not reach significance.

Fears of the supernatural or the unknown were the most prevalent type of fear in this study. In past studies, the fear of animals and the fear of death and danger, which would include environmental hazards such as the tsunami, were the most prevalent among children and adolescents (Gullone and King, 1992; Muris, Merckelback, and Collaris, 1997; Muris et al., 2000). This finding may reflect the fact that this study categorizes fears of people (such as kidnappers) in a grouping of fears of animals and people so as to isolate tsunami-related fears; in prior studies, these fears were categorized as fear of death and danger.

This research finds no relationship between a father's level of education and the reporting of fear, although prior studies have shown that socio-economic status does affect fear levels (Burnham and Gullone, 1997; Erol and Sahin, 1995; Gullone and King, 1992). This may be due to lack of statistical power or issues with how closely a father's level of education approximates current socio-economic status, as described below (see `Study limitations').

This study finds that girls and boys reported fears in general at similar rates. Prior studies, however, have shown that girls report higher overall intensities of fears than boys (Gullone and King, 1992). Both of these findings may be simultaneously true if boys report fears just as often but do not report that they are as intensely afraid as girls do. Unlike previous studies, this research reveals no significant age-related differences in fear reporting, which may be due to lack of power to detect statistical differences upon stratification by age. Previous studies have shown that children who are older report a lower intensity of fear of death and danger and a greater intensity of fear of evaluation and criticism (Gullone and King, 1997). Interestingly, no respondents in this study reported a fear of failure or criticism, which comprises an entire category of fears in the FSSC. This may reflect a smaller role of academic learning in the life of the surveyed children and adolescents compared to the populations where the FSSC was developed. In this sample, based on qualitative data, it was common for older children and adolescents to have dropped out of school to help earn money for the family or take care of younger siblings.

Living in the barracks correlated with having a home closer to the coast prior to the tsunami. This is to be expected since families living closer to the coast were more likely to have lost their homes and required accommodation in barracks. However, the distance of the original home to the coast did not significantly affect the reporting of tsunami-related fears after adjustment for other covariates. Assuming that the distance of the original home to the coast 
was an adequate measure of exposure to the tsunami, this finding suggests that perhaps more than two years after the tsunami, the exposure to the traumatic event may be less influential on children's and adolescents' emotional experience than the living environment. This finding is consistent with those regarding the aftermath of the World Trade Center collapse, during which children who attended schools closer to Ground Zero did not demonstrate higher levels of anxiety or depressive symptoms, but rather lower levels (Hoven et al., 2005).

Research beyond this basic cross-sectional study is required to explain the correlation between living in barracks and reporting tsunami-related fears. However, given the findings that children and adolescents who live in barracks report tsunami-related fears more frequently but report fears in general at rates similar to those living in villages, a phenomenon of fear substitution may be occurring. It may be that immediately after the tsunami, children and adolescents experienced heightened fear of tsunami-related phenomena; the barracks environment may have led to the continued experience or selective reporting of tsunami-related fears, whereas the village environment promoted the substitution of tsunami-related fears by other common fears, such as those of animals or ghosts. This theory is further supported by the finding that children and adolescents living in villages report fears of animals and people more frequently than those living in barracks. The finding that there is no significant difference in the reporting of tsunami-related fears between children who previously lived in barracks and returned to villages and those who never lived in barracks supports the notion that restoration of the village environment may promote substitution of tsunami-related fears by other fears. However, again, since this study takes a cross-sectional approach, the results cannot be used to make conclusions about causality between environment and fears; such interpretations should be made with caution.

There are many possible explanations for how the barracks environment may have led to the continued experience or selective reporting of tsunami-related fears. A recent meta-analysis reports that children and adolescents in detention suffer from a range of anxiety and depressive symptoms that are observed to be `mediated through negative characteristics of the detention environment itself ' (Robjant, Hassan, and Katona, 2009). Although the barracks are not detention camps, they do create an atmosphere quite different from traditional villages, such that it is possible that fears are also mediated in similar ways. The characteristics of the barracks environment may induce the persistence of tsunami-related fears through all three of Rachman's proposed mechanisms of fear acquisition: conditioning, vicarious learning, and information or instruction. The barracks are physically more vulnerable to inclement weather, which would provide more opportunities for fear conditioning among children and adolescents. Given that the children and adolescents moved to the barracks following and as a result of the tsunami, the barracks themselves may have served as a persistent reminder of the disaster, which may have reinforced their fear of the tsunami.

Indirect mechanisms of fear acquisition, namely vicarious learning and information or instruction, may also be at play. Following the 2001 World Trade Center collapse, it was found that family exposure to the attack was an even stronger predictor of probable mental disorder in children than was direct exposure to the event (Hoven et al., 2005). High-level 
media reporting of events following the collapse was also shown to be a risk factor for PTSD in the general population (Laugharne, Janca, and Widiger, 2007). A meta-analysis of childhood phobias shows that children's phobias are highly correlated with the fears of other family members (King, Gullone, and Ollendick, 1998). These findings demonstrate that family members and information delivered to children following the event may have very significant impacts on children's psychological experience following disaster. In the barracks, children's and adolescents' fears may also have been reinforced through their interaction with family members who may have been more affected by the tsunami than people in villages. In addition, more frequent discussion of the tsunami in the barracks-due to a collective experience of being brought together by the disaster-may have served as a form of information or instruction that mediated the persistence of tsunami-related fears among children and adolescents.

Finally, the disruption of social networks and geographical isolation that was brought about by displacement into the barracks may compound the distress of the experience of the tsunami for children and adolescents, as well as for their families. The persistence of tsunami-related fears may be an expression of this magnified distress among children and youths in barracks.

\section{Study limitations}

There are several limitations to this study. As a cross-sectional study and, it can identify a correlation between the living environment and fear reporting but it cannot prove causality between the two variables. The convenience sampling may have selected a population that was more familiar with the village or barracks chiefs or that spent more time outside in the streets and was thus not representative of the entire population. The survey is based on selfreporting and is thus subject to reporting bias. Children and adolescents were asked an openended question about what their fears are rather than being presented with a checklist of fears and a severity rating scale as is done in the FSSC. Thus, there is limited comparability between the results of this study and other studies using the FSSC. By asking children `Are you afraid of anything?', the surveyors obtained a prevalence of self-reporting of fears in general, which has not been assessed or reported in the examined literature. No formal factor analysis was conducted in this study to justify the sub-categorization into the four different types of fears. However, similar categories were elicited as subscales through factor analysis in several previous studies that utilize the FSSC (Burnham and Gullone, 1997; Erol and Sahin, 1995; Muris et al., 2000; Schaefer, Watkins, and Burnham, 2003).

The sample size is relatively small, with only 155 children and adolescents surveyed. When the group of children and adolescents living in villages was broken down into two subgroups - those who previously lived in barracks and those who never did - there were no longer any significant predictors for tsunami-related fears, likely due to the lack of statistical power of the regression model given this stratification. A larger sample size may be necessary to identify fear-reporting patterns between the sub-groups. A larger sample size would also be required to elicit differences in fear reporting related to sex, age, and particular barracks, which may be useful in tailoring interventions for specific groups of children and identifying features of temporary living shelters that are protective for children. 
The distance of the child's home from the coast may not have accurately approximated the exposure to the tsunami, as children were not necessarily at home at the time of the event. It also does not capture potentially traumatic experiences related to the disaster, such as being separated from parents or being injured during the event. Nor does a father's level of education necessarily reflect current socio-economic status. A meta-analysis by Porter and Haslam (2005) associates greater current economic opportunity with superior mental health outcomes, but higher levels of education and socio-economic status prior to displacement are actually associated with worse outcomes among refugees and internally displaced persons. This finding suggests that a father's level of education would have the opposite effect on the mental health outcome than would current economic opportunity; the indicator may thus not have approximated current socio-economic status as was intended, although it did adjust for education and prior socio-economic status.

This study does not assess the severity of the impact of fears on the functioning of children and adolescents. This limits the ability to determine the significance of the main finding, as it is not clear whether tsunami-related fears are actually more debilitating than other types of reported fears. However, in data from qualitative interviews, many parents from both villages and barracks noted that children and adolescents refused to leave the home or attend school when it rained or when there was wind, due to their fears; this finding suggests that tsunami-related fears in this population could have significant effects on development and functionality. As part of a larger psychosocial assessment, functional measures were obtained on the same respondents; the authors intend to analyse the relationship between fears and functionality for a future paper. The significance of fears on functioning among children and adolescents ought to be explored further in future research.

The investigators did not obtain baseline data on child and adolescent fears in this area prior to the tsunami, nor were there prior studies on child and adolescent fears in the Acehnese population. Thus, it is not possible to observe what impact living conditions or the tsunami may have had on the children compared to their baseline. It may be that the reporting of tsunami-related fears among the children who live in barracks is equal to the baseline reporting of these fears among Acehnese children and that it is actually the children living in villages who are now reporting them less frequently, which would change the interpretation of this study greatly. Without knowing common fears in this population, it is also difficult to distinguish between fears and worries or challenges among the responses. Although the two survey questions were asked in a very simple way, there is a chance that children may have understood the questions differently and that some children's fears may have been compared with others' worries, which would make the results difficult to interpret.

In the multivariate analyses, the authors may have failed to measure or adjust for confounders, such as differences in traits of the respondent and parental populations among the different groups. These traits may include linkages with surrounding communities prior to the tsunami, culture and religion, higher levels of stress, coping skills shared by the family, familial losses due to the disaster, predisposition to fearfulness, and the presence of parental psychopathology (Rofi, Doocy, and Robinson, 2006). Certain traits that may have led families to remain in barracks may also have led children of these families to experience more tsunami-related fears. The act of volunteering in the barracks may have differed from 
doing so in a village context. For example, some people in the barracks may have been seeking attention and aid from NGOs through participating in the study; they may thus have been more eager to volunteer than those who were already living in villages. This may have led different sub-groups of respondents with different characteristics to volunteer for the study in these two settings.

The authors did not assess psychopathology among the children and adolescents themselves, although it is very likely that those who live in barracks had higher rates of psychopathology. A prior study demonstrates that PTSD symptoms 2-9 months after the tsunami were higher in prevalence among children displaced to camps (13 per cent) compared to children living in villages (11 per cent), but this did not reach statistical significance $(\mathrm{p}=0.62)$ (Thienkrua et al., 2006). However, a meta-analysis by Porter and Haslam (2005) demonstrates that institutional housing was correlated with worse mental health outcomes among refugees. It is possible that a higher prevalence of PTSD or other anxiety or mood disorders or symptoms among respondents living in barracks led to increased reporting of tsunami-related fears in this sample. Although the purpose of this study is to quantify psychological experience in a non-diagnostic manner-which is why symptoms of psychiatric illness are not assessed—it would have been useful to evaluate anxiety and mood symptoms in order to relate these findings to those of other studies in the field; it would also have been helpful in determining the relationship between anxiety and mood symptoms and fear reporting.

\section{Recommendations}

The results of this study suggest that there are psychological effects on children and adolescents who live in barracks for extended periods of time. Although more research is required to determine the impact of these fears on functioning, the presence of a real difference in psychological experience among children and adolescents living in barracks is still meaningful in the field of post-disaster planning and mental health. In addition to public health and human rights concerns, the psychological effects on children represents yet another compelling reason that the utmost urgency should be placed on restoring people to their homes or their familiar environments. Furthermore, children who have lived in barracks for prolonged periods may have different mental health needs compared to children who have not, specifically regarding issues of displacement. The lack of effect of tsunami exposure on the reporting of tsunami-related fears demonstrates that after more than two years, the living environment may play a greater role than the actual event in driving fears. Thus, rather than focusing on the disaster, perhaps interventions should address displacement itself through strategies, such as normalizing children's and adolescents' living environments.

Key contributions of this study include the assessment of the long-term mental health outcomes for tsunami-affected children and adolescents, the evaluation of the impact of prolonged displacement on these outcomes, and the characterization of these outcomes through a non-diagnostic measure. More studies characterizing the population through nondiagnostic constructs, such as fears, worries, or functional measures, are needed in settings where psychiatric diagnoses are not yet validated or where respondents are not able to 
receive appropriate medical attention (Bird et al., 2005; Lee et al., 2008). These constructs may be more helpful in understanding the population's needs as well as in designing appropriate interventions. More studies are also needed to assess the intermediate and longterm impact of disasters on populations to better inform the reconstruction of communities.

\section{Conclusion}

This study demonstrates that children and adolescents who have lived in barracks for at least 30 months after the tsunami are more likely to report tsunami-related fears than are children who live in villages. The psychological impact on children should serve as another compelling reason for those in power to minimize the duration of temporary housing of disaster victims and to attempt to rebuild communities as quickly as possible. The interventions for children and adolescents with prolonged displacement should focus more attention on normalizing their environment to create a sense of recovery.

\section{Acknowledgments}

The authors thank the International Organization for Migration of Meulaboh, Indonesia, for making this study possible.

\section{References}

Bauer DH. `An exploratory study of developmental changes in children's fears'. Journal of Child Psychology and Psychiatry. 1976; 17:69-74. [PubMed: 765351]

Belfer ML. 'Caring for children and adolescents in the aftermath of natural disasters'. International Review of Psychiatry. 2006; 18(6):523-8. [PubMed: 17162692]

Bird HR, et al. `The Brief Impairment Scale (BIS): a multidimensional scale of functional impairment for children and adolescents'. Journal of the American Academy of Child \& Adolescent Psychiatry. 2005; 44(7):699-707. [PubMed: 15968239]

Burnham JJ, Gullone E. `The Fear Survey Schedule for Children-II: a psychometric investigation with American data'. Behaviour Research Therapy. 1997; 35(2):165-73. [PubMed: 9046680]

Erol N, Sahin N. 'Fears of children and the cultural context: the Turkish norms'. European Child and Adolescent Psychiatry. 1995; 4(2):85-93. [PubMed: 7796254]

Fullilove MT. 'Psychiatric implications of displacement: contributions from the psychology of place'. American Journal of Psychiatry. 1996; 153(12):1516-23. [PubMed: 8942445]

Gullone E, King NJ. 'The fears of youth in the 1990s: contemporary normative data'. Journal of Genetic Psychology. 1992; 154(2):137-53. [PubMed: 8366328]

Gullone E, King NJ. `Three-year follow-up of normal fear in children and adolescents aged 7 to 18 years'. British Journal of Developmental Psychology. 1997; 15(1):97-111.

Hoven CW, et al. 'Psychopathology among New York city public school children 6 months after September 11'. Archives of General Psychiatry. 2005; 62(5):545-52. [PubMed: 15867108]

Ingman KA, Ollendick TH, Akande A. 'Cross-cultural aspects of fears in African children and adolescents'. 1999; 37(4):337-45.

John PB, Russell S, Russell PS. 'The prevalence of posttraumatic stress disorder among children and adolescents affected by tsunami disaster in Tamil Nadu'. Disaster Management Response. 2007; 5(1):3-7. [PubMed: 17306747]

Karairmak O, Aydin G. `Reducing earthquake-related fears in victim and nonvictim children'. Journal of Genetic Psychology. 2008; 169(2):177-85. [PubMed: 18578300]

King NJ, Gullone E, Ollendick TH. `Etiology of childhood phobias: current status of Rachman's three pathways theory'. Behaviour Research Therapy. 1998; 36:297-309. [PubMed: 9642849] 
Laugharne J, Janca A, Widiger T. 'Postraumatic stress disorder and terrorism: 5 years after 9/11'. Current Opinion Psychiatry. 2007; 20(1):36-41.

Lee, CT., et al. Displacement as a Predictor for Impaired Functioning in Tsunami-afflicted Children. Paper presented at the International Association of Child and Adolescent Psychiatry Conference; Istanbul, Turkey. 2008.

Muris P, Merckelback H, Collaris R. 'Common childhood fears and their origins'. Behavioral Research Therapy. 1997; 35(10):929-37.

Muris P, et al. 'Fears, worries, and scary dreams in 4- to 12-year-old children: their content, developmental pattern, and origins'. Journal of Clinical Child Psychology. 2000; 29(1):43-52. [PubMed: 10693031]

Ollendick TH. 'Reliability and validity of the Revised Fear Survey Schedule for Children (FSSC-R)'. Behaviour Research and Therapy. 1983; 21(6):685-92. [PubMed: 6661153]

Ollendick, TH. `The Fear Survey Schedule for Children (FSSC-R). (n.d.)http:// www.childrenandwar.org//measures/measures-by-others/

Piaget, J. Le développement de la notion de temps chez l'enfant. Presses Universitaires de France; Paris: 1946.

Piyasil V, et al. 'Post traumatic stress disorder in children after tsunami disaster in Thailand: 2 years follow-up'. Journal of the Medical Association of Thailand. 2007; 90(11):2370-6. [PubMed: 18181322]

Porter M, Haslam N. 'Predisplacement and postdisplacement factors associated with mental health of refugees and internally displaced persons: a meta-analysis'. JAMA. 2005; 294(5):602-12. [PubMed: 16077055]

Rachman S. 'The conditioning theory of fear-acquisition: a critical examination'. Behaviour Research Therapy. 1977; 15:375-87. [PubMed: 612338]

Rao K. 'Psychosocial support in disaster-affected communities'. International Review of Psychiatry. 2006; 18(6):501-5. [PubMed: 17162689]

Robjant K, Hassan R, Katona C. `Mental health implications of detaining asylum seekers: a systematic review'. British Journal of Psychiatry. 2009; 194(4):306-12. [PubMed: 19336779]

Rofi A, Doocy S, Robinson C. 'Tsunami mortality and displacement in Aceh province, Indonesia'. Disasters. 2006; 30(3):340-50. [PubMed: 16911432]

Schaefer BA, Watkins MW, Burnham JJ. `Empirical fear profiles among American youth'. Behaviour Research Therapy. 2003; 41(9):1093-103. [PubMed: 12914810]

Stichick T. 'The psychosocial impact of armed conflict on children: rethinking traditional paradigms in research and intervention'. Child and Adolescent Psychiatry Clinics of North America. 2001; 10(4):797-814.

Summerfield D. 'The invention of post-traumatic stress disorder and the social usefulness of a psychiatric category'. British Medical Journal. 2001; 322:95-8. [PubMed: 11154627]

Thienkrua W, et al. 'Symptoms of posttraumatic stress disorder and depression among children in tsunami-affected areas in southern Thailand'. JAMA. 2006; 296(5):549-59. [PubMed: 16882961]

Ulartinon S, et al. 'Assessment of psychopathological consequences in children at 3 years after tsunami disaster'. Journal of the Medical Association of Thailand. 2008; 91(3):S69-75. [PubMed: 19253499]

USAID (United States Agency for International Development). `Indian Ocean: earthquakes and tsunamis'. 2005. Fact Sheet No. 39. 7 July. http://www.usaid.gov/our_work/ humanitarian_assistance/disaster_assistance/countries/indian_ocean/fy2005/ indianocean_et_fs39_07-07-2005.pdf

Vijayakumar L, Kannan GK, Daniel SJ. 'Mental health status in children exposed to tsunami'. International Review of Psychiatry. 2006; 18(6):507-13. [PubMed: 17162690] 


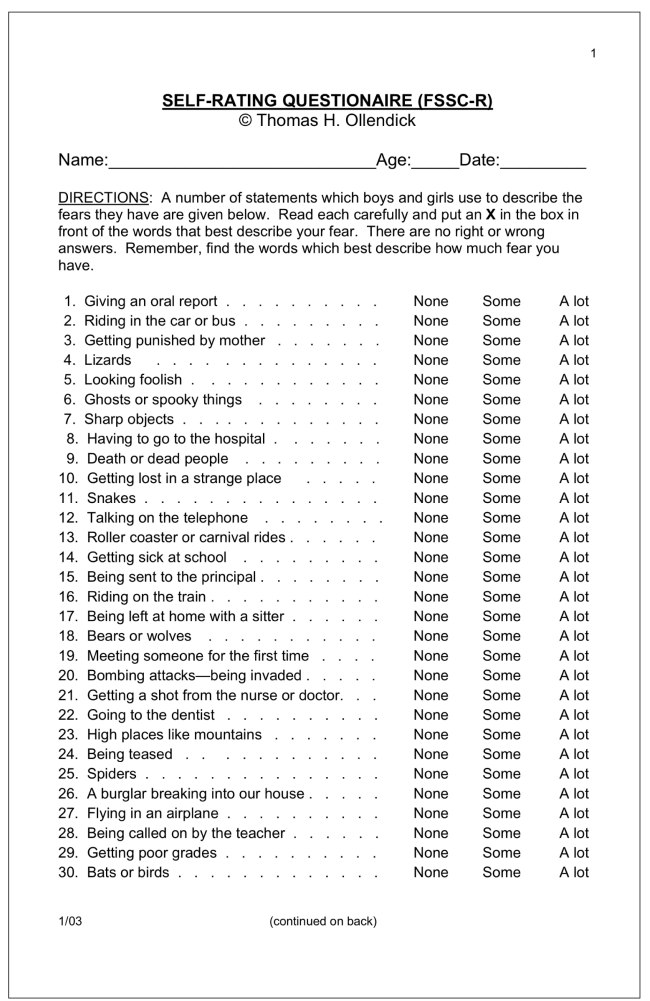

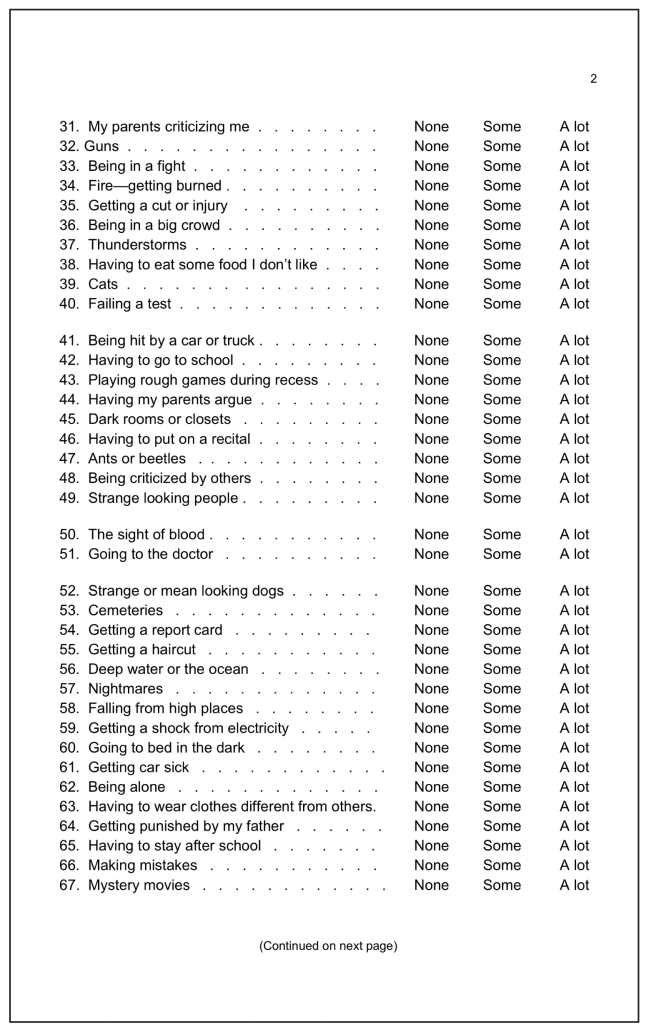

Disasters. Author manuscript; available in PMC 2014 April 18. 


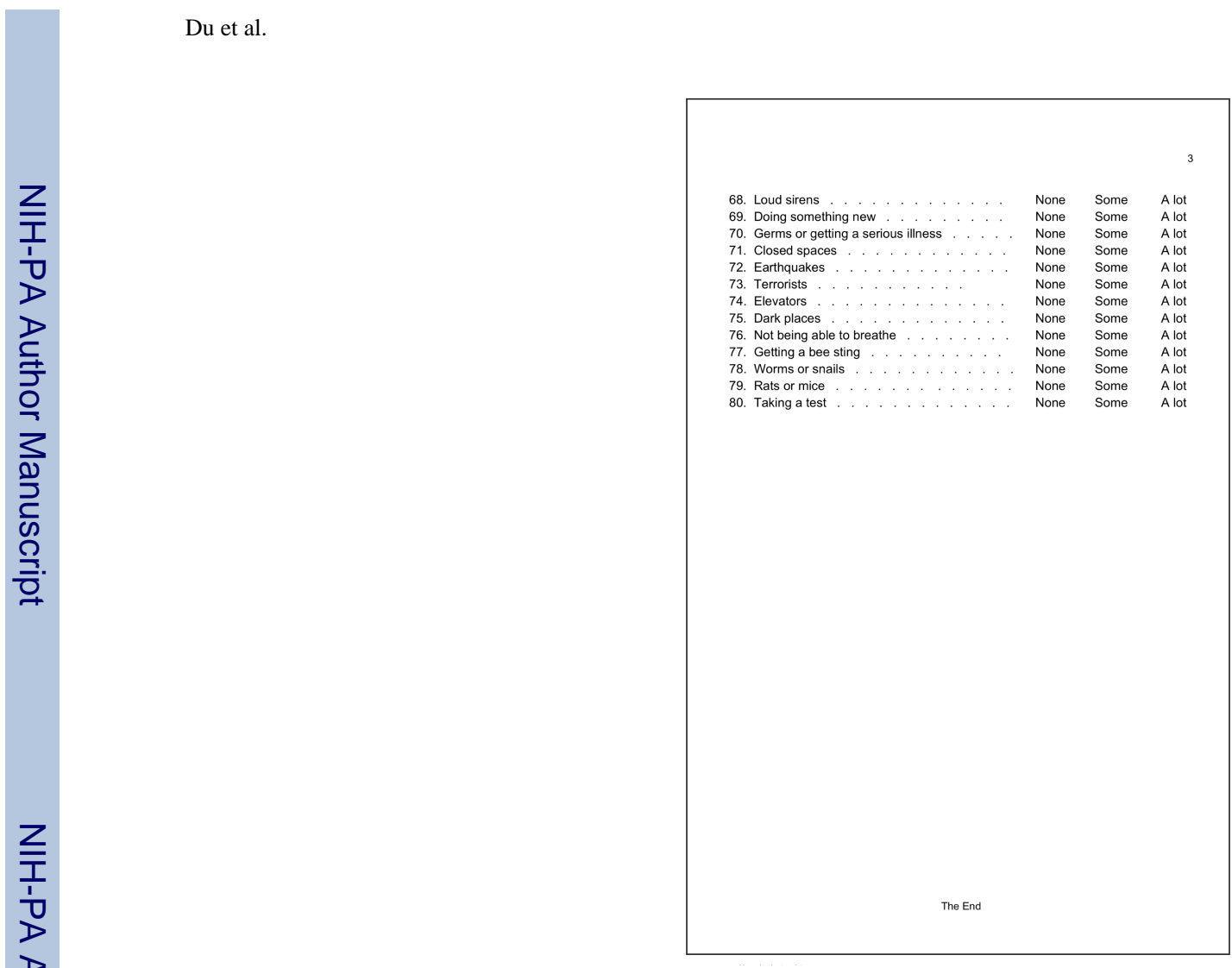

Figure 1.

The Fear Survey Schedule for Children-R

Disasters. Author manuscript; available in PMC 2014 April 18. 


\section{Table 1}

\section{Categorization of reported fears}

\begin{tabular}{|c|c|}
\hline Category of fear & Specific fears included \\
\hline \multirow[t]{4}{*}{ Tsunami-related } & Tsunami \\
\hline & Wind \\
\hline & Storm \\
\hline & Earthquake \\
\hline \multirow[t]{14}{*}{ Animals and people } & Snakes \\
\hline & Tigers \\
\hline & Pigs \\
\hline & Lions \\
\hline & Elephants \\
\hline & Gorillas \\
\hline & Dogs \\
\hline & Camels \\
\hline & Birds \\
\hline & Reptiles \\
\hline & Rhinoceros \\
\hline & Police \\
\hline & People/bad people/kidnappers \\
\hline & Mother/father/brother \\
\hline \multirow[t]{5}{*}{ Supernatural or unknown } & Ghosts \\
\hline & The devil \\
\hline & Skeletons \\
\hline & Gutters \\
\hline & The future \\
\hline God & God \\
\hline
\end{tabular}




\section{Table 2}

Sample demographic characteristics

\begin{tabular}{|l|l|l|l|l|l|}
\hline Characteristics & BAR & VIL & VIL-B & VIL-V & Total \\
\hline Number in group (as \% of respondents) & $62(40.0 \%)$ & $93(60.0 \%)$ & $27(17.4 \%)$ & $66(42.6 \%)$ & $155(100 \%)$ \\
\hline Girls (as \% of respondents) & $26(41.9 \%)$ & $46(49.5 \%)$ & $14(51.9 \%)$ & $32(48.5 \%)$ & $72(46.5 \%)$ \\
\hline Boys (as \% of respondents) & $36(58.1 \%)$ & $47(50.5 \%)$ & $13(48.1 \%)$ & $34(51.5 \%)$ & $83(53.6 \%)$ \\
\hline 5-6-year-olds (as \% of respondents) & $7(11.3 \%)$ & $4(4.3 \%)$ & $0(0.0 \%)$ & $4(6.1 \%)$ & $11(7.1 \%)$ \\
\hline 7-11-year-olds (as \% of respondents) & $34(54.8 \%)$ & $57(61.3 \%)$ & $15(55.5 \%)$ & $42(63.6 \%)$ & $91(59.1 \%)$ \\
\hline 12-14-year-olds (as \% of respondents) & $20(32.2 \%)$ & $32(34.4 \%)$ & $12(44.4 \%)$ & $20(30.3 \%)$ & $52(33.8 \%)$ \\
\hline Age (mean) & 9.2 & 9.6 & 10.3 & 9.3 & 9.5 \\
\hline Father's mean education (range) & $1.7(0-3)$ & $2(0-4)$ & $2(0-4)$ & $2(0-4)$ & $1.9(0-4)$ \\
\hline Mean distance of original home from coast (range), in km & $1.1(0-10)$ & $3.4(0-20)$ & $1.1(0-2.5)$ & $4.7(0.1-20)$ & $2.4(0-20)$ \\
\hline
\end{tabular}




\section{Table 3}

Fear-reporting charactenstics

\begin{tabular}{|l|l|l|l|l|l|}
\hline Fears & Entire sample & Village children & Barracks children & $\begin{array}{l}\text { Unadjusted odds } \\
\text { ratio (confidence } \\
\text { interval) }\end{array}$ & $\begin{array}{l}\text { Adjusted odds } \\
\text { ratio (confidence } \\
\text { interval) }\end{array}$ \\
\hline Reporting fears in general & $69.7 \%$ & $79.6 \%$ & $54.8 \%$ & $0.31(0.15-0.63)$ & $0.52(0.22-1.24)$ \\
\hline Reporting tsunami-related fears & $23.4 \%$ & $16.2 \%$ & $38.2 \%$ & $3.36(1.32-8.53)$ & $2.97(1.00-8.84)$ \\
\hline $\begin{array}{l}\text { Reporting fears of animals and } \\
\text { people }\end{array}$ & $41.1 \%$ & $45.9 \%$ & $29.4 \%$ & $0.51(0.21-1.22)$ & $0.30(0.10-0.90)$ \\
\hline Reporting fears of the supernatural & $50.5 \%$ & $51.4 \%$ & $47.1 \%$ & $0.89(0.39-2.03)$ & $0.96(0.34-2.67)$ \\
\hline Reporting a fear of god & $9.4 \%$ & $9.5 \%$ & $8.8 \%$ & $0.96(0.23-3.96)$ & $0.75(0.14-4.02)$ \\
\hline
\end{tabular}

